\title{
Appraisal, Agency and Atypicality: Evidence from Manufactured Homes
}

\author{
Dennis R. Capozza, ${ }^{*}$ Ryan D. Israelsen** and Thomas A. Thomson***
}

The appraisal of the "market value" of homes serving as the collateral for mortgages is a fundamental part of the underwriting process. If a loan should default, however, it is not the retail market value that the lender obtains, but rather the "recovery value." In this research, we show how recovery values differ from market values at origination and explore the reasons for the differences. Using a large sample of chattel mortgages on manufactured homes, we explore the relationship among the selling prices, the book values, and the fitted values from simple hedonic models with spatial autocorrelation. We then address the differences between selling prices at origination and recoveries from repossessed homes. We find that the spread between them varies systematically with home characteristics and especially with "atypicality," that is, with measures of how unusual a home is. Selling prices both at origination and recovery affect borrower defaults.

For decades, property appraisal has been a mainstay of mortgage underwriting and is an essential element of the verification process for lenders. The appraiser provides a professional estimate of the value of the property that can be used to verify that the selling price is representative of current market conditions. The lender uses the appraisal to assess whether the loan will perform, that is, repay in full, and whether the loan will be profitable for the lender. But is the simple point estimate sufficient for assessing the risks associated with the collateral? Can lenders improve loan decisions with information on the expected second moment or with estimates of the likely recovery values from a default?

In this research, we explore these issues with a large data set of chattel mortgages on manufactured homes. Manufactured homes, although little researched, are an increasingly important segment of the housing market. The Manufactured Housing Institute reports that $8 \%$ of the U.S. population lives in manufactured homes. In 2001, manufactured homes made up about $15 \%$ of residential starts.

${ }^{*}$ Ross School of Business, University of Michigan, Ann Arbor, MI 48109 or capozza@umich.edu.

**Ross School of Business, University of Michigan, Ann Arbor, MI 48109 or risraels@umich.edu.

*** Department of Finance, College of Business University of Texas, San Antonio, TX 78249 or tthomson@utsa.edu. 
Chattel mortgages, unlike conventional single-family mortgages, are secured only by the structure or "home" and do not include a lien on the underlying land. In most cases, the borrower does not own the land. Instead, the land is either rented from a third-party owner or from the owner of a manufactured housing "park," which, like a single-family subdivision, often groups similar homes in one location. ${ }^{1}$ In parks, the land leases are usually month-to-month.

The foreclosure or repossession process can be much quicker and simpler for manufactured homes because the collateral is mobile, albeit at a nontrivial cost. ${ }^{2}$ At most times, dealers provide a ready market for repossessed units, although occasionally they are overstocked with inventory and unwilling to provide the usual level of liquidity to the market.

There are many reasons to question the optimality of existing appraisal procedures for residential mortgages in general and manufactured homes specifically. First, there may be agency issues in the appraisal process. Appraisers, like all parties to real estate transactions, are often subjected to pressures or incentives to shade their estimates so that the transaction will be approved. Loan volume drives the compensation of many participants in the process and inevitably colors all of the participants at least indirectly.

There has been a fair amount of recent experimental research investigating appraisers' incentives and biases. For example, it has been shown that appraisers may be influenced by valuations of others (Diaz 1997) and by their own previous appraisals (Diaz and Wolverton 1998). A number of studies find that clients may influence the valuations. ${ }^{3}$

Even more basic to the appraisal process is whether appraisals are unbiased estimates of market values. It is well known that appraisals lag behind market movements (Quan and Quigley 1989). Appraisals can also be unbiased but inaccurate. ${ }^{4}$

\footnotetext{
${ }^{1}$ It is also possible for units to be placed on owned land and for the lender to have a lien on both the land and the home. These "land homes," then, are very similar to conventional mortgages, but are not included in our data. Other times, manufactured homes are installed on a permanent foundation and become largely indistinguishable from traditional "stick" built homes. Loans on these kinds of manufactured homes are not included in our data.

${ }^{2}$ Repossessed units are often wholesaled to dealers and hauled away to the dealer's sales lot where they are reconditioned and resold for a profit.

${ }^{3}$ See Kinnard, Lenk and Worzala (1997), Levy and Schuck (1999), Wolverton and Gallimore (1999) and Hansz and Diaz (2001).

${ }^{4}$ Cole, Guilkey and Miles (1986) made an ex post comparison of the most recent independent appraisal to subsequent sales prices of 144 commercial properties and found
} 
A third issue is whether there is a link between appraisal quality and probability of default. Lenders use appraisals to help evaluate the probability of default. Loan-to-value ratios (LTVs) are widely used as a causal variable in statistical modeling of default probabilities. Noordewier, Harrison and Ramagopal (2001), using a sample of 1,428 residential loans, find evidence that properties that are valued above the sales price of "similar and proximate" properties are more prone to default. However, they conclude that the simple variance of property values is not related to default. Lacour-Little and Malpezzi (2003) find that decreasing appraisal quality is associated with an increase in the probability of default. In addition, they find that over-appraisal is significantly related to default, while under-appraisal is not. We have been unable to find any studies of the relationship of point estimates and dispersion estimates of property value and collateral value, which is ultimately what determines recovery risks.

But are current LTVs, whether based on purchase prices or appraisals, the appropriate driver for default equations? At the time of the default decision, the borrower will typically be distressed and the relevant value may not be a retail value. A forced or distressed sale will occur at a reduced price, which may be more relevant for assessing default probabilities at origination. Liquid properties where an owner can obtain a quick sale at only a small discount from market prices may have lower default probabilities because borrowers will be able to avoid default by selling. If, on the other hand, a property is unusual and difficult to sell, default may be the best alternative. Therefore, understanding the marketability and the liquidity of properties may help evaluate loan performance.

It is certainly the case that appraisals are an inappropriate metric for understanding the expected profitability of loans (Guttentag 1992, Capozza and Thomson 2005). Assessing profitability requires that lenders estimate all the future cash flows on the loan including the recoveries from defaulted loans. For this task, estimates of the recovery values will be more useful than estimates of the market value at origination. Therefore, while appraised values, that is, estimates of the market value at origination, are the most commonly used in underwriting, it may be that lenders should estimate recovery or wholesale values. If recovery values are a better predictor of defaults than appraised values, then appraised values

an average absolute difference of about $9 \%$. Using a sample of 500 properties acquired by corporate relocation firms, Dotzour (1988) found that current appraisal methods were unbiased estimates of value and that a large part of the variation in appraisal error could be accounted for with seasonal factors and regional economic conditions. Chinloy, Cho and Megbolugbe (1997) conclude, using a sample of 3.7 million repeat transactions on mortgages bought by Fannie Mae and Freddie Mac, that appraisals are systematically higher than purchase data. However, a drawback of using sales price to evaluate appraisal quality is that low appraisals tend to be correlated with rejected loans, and are therefore not included in the samples. 
are superfluous. If, on the other hand, appraised values are a better predictor of defaults, then estimates of both market values at origination and recovery values in default will be needed.

From the borrower perspective, both the appraisal (retail values) and the distressed or recovery values should be relevant. If the borrower is subject to financial stress and cannot make payments, the first choice is to sell the property to a retail buyer and prepay the loan, thereby salvaging any equity. When trying to sell to a retail buyer, the liquidity of the property will matter. Illiquid properties will be less likely to sell, reducing the chance that the borrower can repay the loan. The difference between the retail value and the recovery value is a measure of the liquidity of the property similar to the bid-ask spread in other financial markets. If the property does not sell to a retail buyer, the borrower may be forced into foreclosure. Therefore, there are many moving parts in the borrower's decision. Both the appraised value and the estimated recovery value play a role and should be included in the lender's assessment of risks and expected losses.

As part of our analysis, we explore two measures of liquidity and heteroskedasticity in some detail. The first, atypicality, (Haurin 1988) is a measure of how unusual a unit is relative to an average unit. The second, sparsity, measures the number of units that have sold recently within a 15-mile radius. Of the two, atypicality is a more important factor in hetroskedasticity.

In the next section, we describe the data and follow with a discussion of the methodology. The third section presents the results of our empirical analysis, which is divided into eight subsections. We first estimate hedonic models of selling prices that exploit spatial autocorrelation and include our measures of atypicality and sparsity. The next subsection compares the 1-year forecast performance of the various models and shows that the best models have mean squared errors (MSEs) of 6-7\%. We then compare the results from using the selling price, the appraised value and the various hedonic models for predicting recovery values for repossessions and show that the simplest hedonic models are the best predictors of recoveries. These results suggest that valuation for recovery is quite different from the valuation of selling prices at origination.

The fourth subsection analyzes the characteristics that are important for the retail sales (at origination) versus the wholesale prices (recoveries). The fifth subsection analyzes the forecast errors and shows that atypical units have larger forecast errors. This suggests that models of automated appraisal should adjust for atypicality and lenders should incorporate this information into profitability estimates. The sixth subsection compares models of default that use selling price, appraisal, automated appraisal and recovery estimates to calculate LTVs. 
In the last subsection we document that both manual appraisals and simple statistical hedonic or automated appraisals improve the predictions of default models. Automated and manual appraisals perform about equally well. Estimates of the recovery value also significantly improve risk assessment. The final section summarizes and concludes.

\section{Data}

Our data are a large sample of loans from the manufactured housing industry. The data include 195,442 observations of manufactured homes at the time of loan origination and the subsequent recovery information for 9,746 of the homes that defaulted. All of the homes are located on rented land. Variables in the origination database include information about the loan:

Sales price $=$ the purchase price (market price) of the home.

Book or appraised value $=$ the book value or appraised value of the home. ${ }^{5}$

Origination date $=$ the month of loan origination.

Termination date $=$ the final month of data for the loan.

Refinance $=$ a dummy variable indicating that the loan is a refinance of an existing loan.

Variables also include information about the collateral:

Length $=$ the length of the home.

Width $=$ the width of the home.

Model year $=$ the model year of the home.

ZIP code $=$ ZIP code of the location of the home.

Park $=$ a dummy variable indicating that the home is located in a manufactured housing park.

Multi-wide home $=$ a dummy variable indicating that the home is multi-wide.

Resale of repossessed home $=$ a dummy variable indicating that the unit was a former repo.

Manufacturer 1-Manufacturer $13=$ dummy variables indicating the manufacturer of the home.

If a unit is repossessed and sold, the following data are available:

Repo sale price $=$ the price for which the repossessed unit sold (the second sales observation).

\footnotetext{
${ }^{5}$ As in the auto lending industry, the collateral value or "book value" is typically estimated from standard industry guides that provide estimates of value based on market, make, model, year and equipment. Occasionally, however, a full residential appraisal is done.
} 
Number of baths $=$ the number of baths in the repossessed unit. Condition $=$ the physical condition of the repossessed unit.

In addition to the variables in the database, we created several others. The postal ZIP code data can be assigned a latitude and longitude. From these coordinates for each sale, we calculated the distance between observations and created a variable, SPARSITY, which is a measure of proximity to other recent sales. SPARSITY is the reciprocal of 1 plus the number of sales within a 15-mile radius during the previous year:

$\operatorname{SPARSITY}_{i}=\frac{1}{1+N_{i}}$

where $N_{i}$ is the number of sold homes within 15 miles of the $i$ th home. Note that

$\operatorname{SPARSITY}_{i} \in[0,1], \forall i, \lim _{N_{i} \rightarrow 0} \operatorname{SPARSITY}_{i}=1, \quad$ and

$$
\lim _{N_{i} \rightarrow \infty} \operatorname{SPARSITY}_{i}=0 .
$$

(As the number of home sales near the $i$ th home increases, SPARSITY approaches 0 , and when there are no homes within 15 miles of the $i$ th home, its value is 1.)

Because new units come with a manufacturer's invoice price instead of a manual appraisal, we limit our study to those homes that were previously owned at the time of origination. Table 1 presents summary statistics for the variables.

To account for the difficulty that arises in valuing homes with unusual features, we created a variable, ATYPICAL, following the approach outlined in Haurin (1988). We use implicit marginal prices from a semi-log hedonic regression of home sales prices on various characteristics to penalize absolute deviations from the average (see the Appendix for a more complete discussion). Thus, the weights used to generate the ATYPICAL variable are percentage influences on value rather than absolute dollar prices.

\section{Results}

\section{Hedonic Models with Spatial Autocorrelation}

We begin with a standard hedonic regression of the log of real sales price on the available set of characteristics. The results are presented in Table 2, panel A, first column. The most significant independent variables include the age 
Table 1 - Summary statistics.

\begin{tabular}{|c|c|c|c|c|c|}
\hline Variable & Mean & Std. Dev. & Max. & Min. & $N$ \\
\hline Sale price & $\$ 19,757$ & $\$ 10,244$ & $\$ 75,000$ & $\$ 2,300$ & 195,442 \\
\hline Appraised value & $\$ 21,783$ & $\$ 11,233$ & $\$ 75,000$ & $\$ 1,000$ & 195,442 \\
\hline Latitude & 38 & 5 & 66 & 19 & 193,843 \\
\hline Longitude & -92 & 13 & -67 & -167 & 193,843 \\
\hline Age of unit at origination (months) & 116 & 73 & 408 & 12 & 195,442 \\
\hline Model year & 1985 & 6 & 1999 & 1963 & 195,442 \\
\hline Length of unit (feet) & 65 & 10 & 80 & 40 & 195,442 \\
\hline Width of unit (feet) & 17 & 5 & 40 & 12 & 195,442 \\
\hline Repo sale price & $\$ 10,808$ & $\$ 9,330$ & $\$ 95,000$ & $\$ 200$ & 8,941 \\
\hline Location $=$ park & 0.85 & & 1 & 0 & 195,442 \\
\hline Multi-wide home & 0.24 & & 1 & 0 & 195,442 \\
\hline Origination date ( 1 = January 1987 ) & 101 & 35 & 150 & 1 & 195,442 \\
\hline Termination date & 134 & 25 & 150 & 6 & 195,442 \\
\hline Loan-to-value at origination & 0.89 & 0.1 & 1.1 & 0.2 & 135,638 \\
\hline Loan term & 172 & 71 & 360 & 24 & 135,638 \\
\hline Loan age & 34 & 25 & 150 & 1 & 195,442 \\
\hline Borrower credit score & 650 & 64 & 840 & 430 & 116,242 \\
\hline Baths per $1,000 \mathrm{SF}$ & 1.6 & 0.4 & 4.2 & 0.6 & 195,442 \\
\hline Baths unknown & 0.9 & 0.2 & 1.0 & 0.0 & 195,442 \\
\hline Spatial lag & 9.4 & 0.3 & 10.8 & 8.5 & 195,442 \\
\hline Sparsity & 0.1 & 0.2 & 1.0 & 0.0 & 195,442 \\
\hline Atypicality & 0.5 & 0.3 & 1.6 & 0.1 & 195,442 \\
\hline Manufact & 0.01 & & 1 & 0 & 195,442 \\
\hline Manufacturer 2 & 0.02 & & 1 & 0 & 195,442 \\
\hline Manufacturer 3 & 0.01 & & 1 & 0 & 195,442 \\
\hline Manufacturer 4 & 0.02 & & 1 & 0 & 195,442 \\
\hline Manufacturer 5 & 0.01 & & 1 & 0 & 195,442 \\
\hline Manufacturer 6 & 0.00 & & 1 & 0 & 195,442 \\
\hline Manufacturer 7 & 0.00 & & 1 & 0 & 195,442 \\
\hline Manufacturer 8 & 0.01 & & 1 & 0 & 195,442 \\
\hline Manufacturer 9 & 0.01 & & 1 & 0 & 195,442 \\
\hline Manufacturer 10 & 0.01 & & 1 & 0 & 195,442 \\
\hline Manufacturer 11 & 0.00 & & 1 & 0 & 195,442 \\
\hline Manufacturer 12 & 0.01 & & 1 & 0 & 195,442 \\
\hline Manufacturer 13 & 0.00 & & 1 & 0 & 195,442 \\
\hline
\end{tabular}

Notes: This table displays selected summary statistics for the collateral and the loans. Variable names are self-explanatory. Missing loan amount data limit the number of loan-to-value observations to 135,638 . Sparsity is defined as $1 /(1+N)$ where $N$ is the number of homes sold within 15 miles in the previous year. Atypicality is defined in Equation (2) in the text. Spatial lag is a weighted sum of the log of sales prices as defined in Equation (A.1).

of the home, the size of the home and whether the unit is single or multiwide. The coefficients indicate that each month a home depreciates by 30 basis points or $3.6 \%$ per year. Each 100 square feet adds $10 \%$ to value. For any given size unit, a multi-wide configuration is worth $35 \%$ more. Location in a 


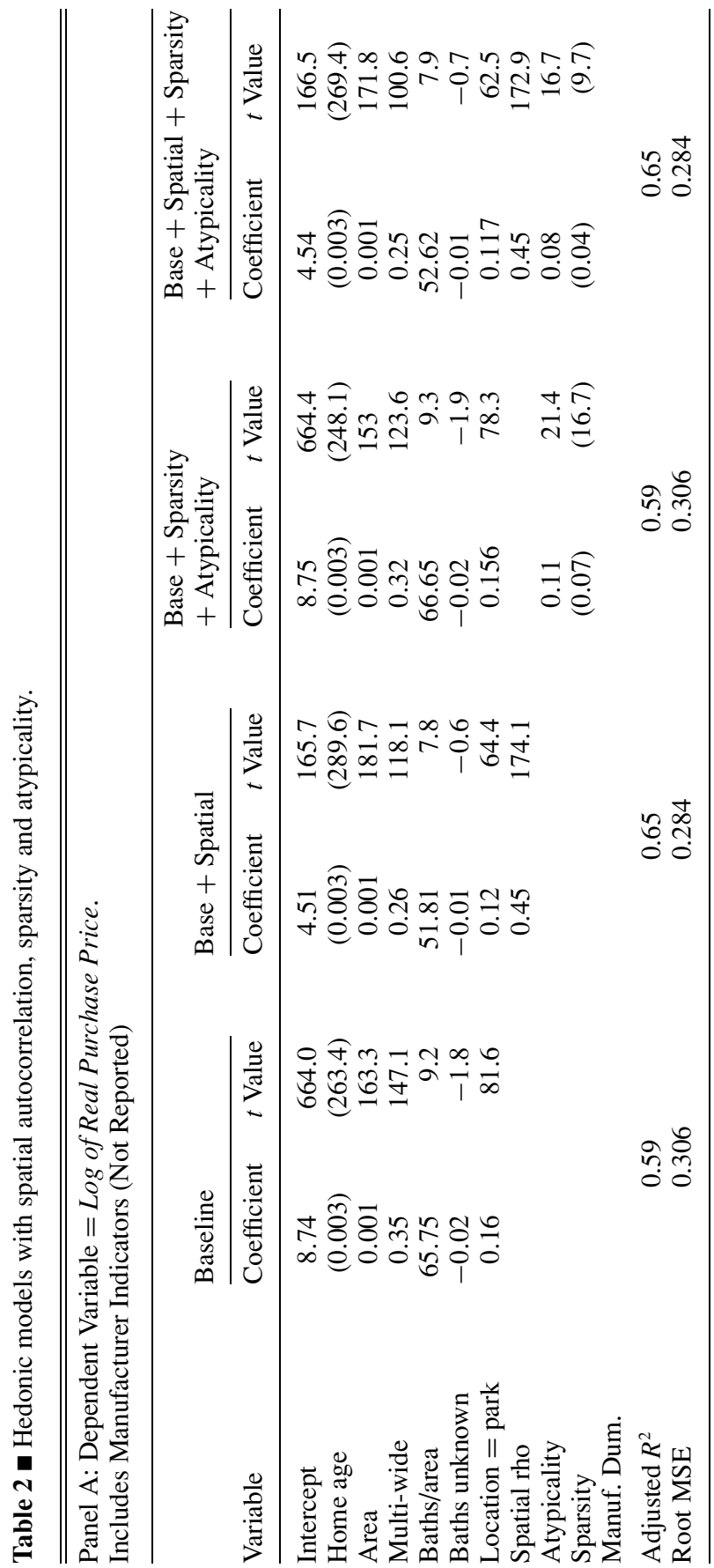




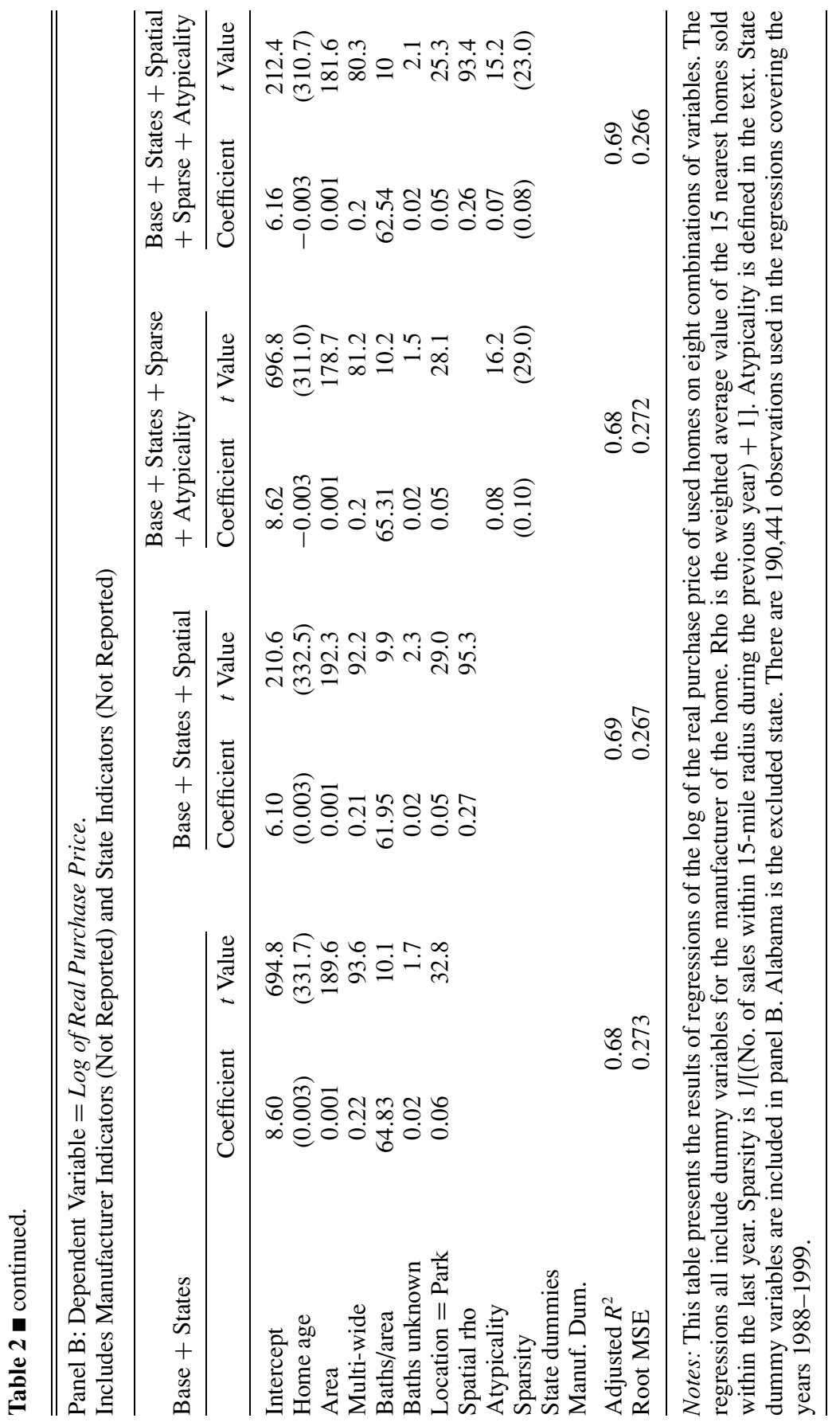


manufactured housing park is worth $16 \%$ more. Extra baths add to value, but are not highly significant, perhaps because this variable is sparsely populated in the database. Manufacturer indicator variables were included in all the equations in Table 2, but are not reported. In the second equation of panel A, we adjust for spatial autocorrelation by including a weighted average of the surrounding sales as described in the Appendix. This spatial variable is highly significant and reduces the MSE. In the third equation of panel A, the SPARSITY and ATYPICAL variables are included, but not spatial autocorrelation. SPARSITY and ATYPICAL are significant, but add little to the fit and accuracy of the model.

In panel $\mathrm{B}$, we present identical regressions but now including state indicator variables. The addition of the 50 state indicators does improve the fit relative to panel A. The second equation in panel B shows that spatial autocorrelation is still an economically important and statistically significant variable even when state indicators are included.

\section{Out-of-Sample Forecast Performance}

In Table 3, we present the results of our test of out-of-sample forecast accuracy of the eight models in Table 2. We first train the model on an initial sample of data, and then use the estimates to forecast sales prices 1 year ahead. Each year the model is "retrained" using an additional year of data. Table 3 displays the MSEs by year and by model from this experiment.

In each year, the most accurate models include both the state indicators and the spatial autocorrelation variable. This suggests that local factors play an important role in the price of manufactured homes. One curious result in Table 3 is the tendency for the MSEs for all the models to become larger over time despite being trained on extra years of data. This suggests that the prices of these homes became more disperse and more difficult to explain over time.

\section{The Value of Recovered Units}

In Table 4, we begin to explore the relationship between purchase prices and recovery liquidation prices. We do so by regressing the log of the real recovery price on one of several estimates of the value of the home at originationthe actual purchase price, the book or appraised value and six of the hedonic estimates from Table 2. Also included in each equation are indicator variables for the condition of the home (poor, fair, good) and for the sales channel (refinance, wholesale, cash, redemption). The loan age at the time of default is included as a measure of the depreciation since origination. 


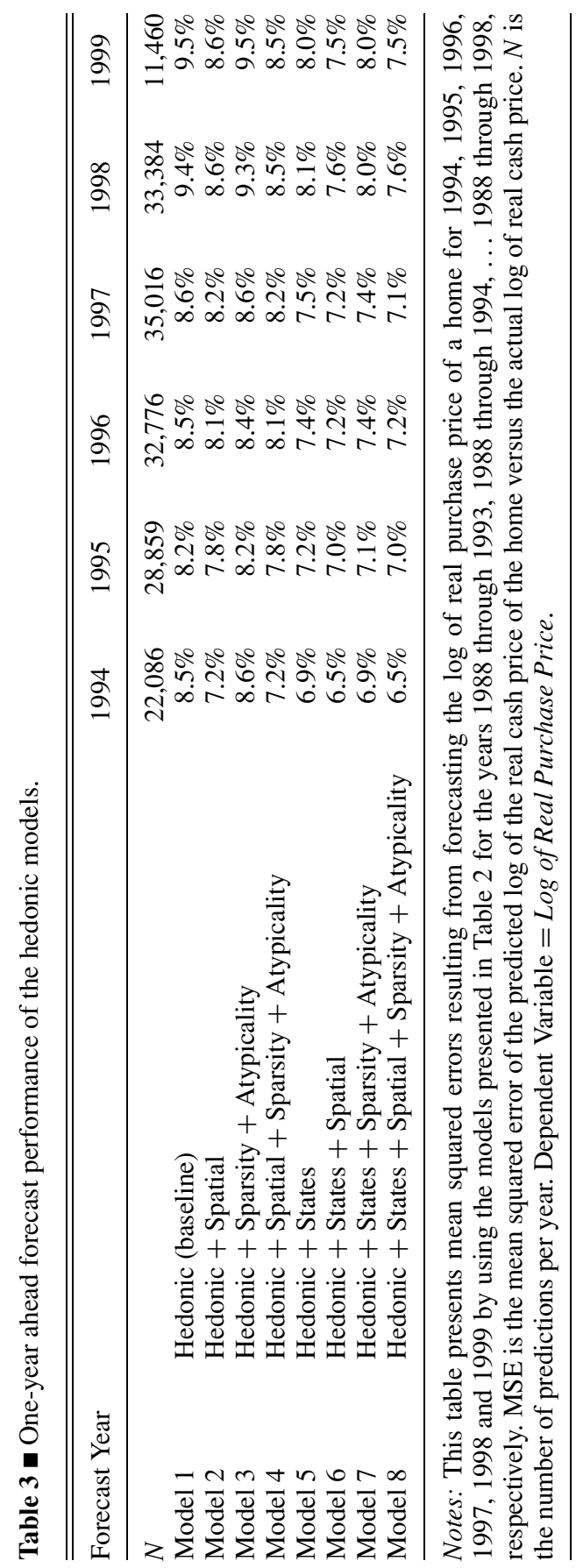




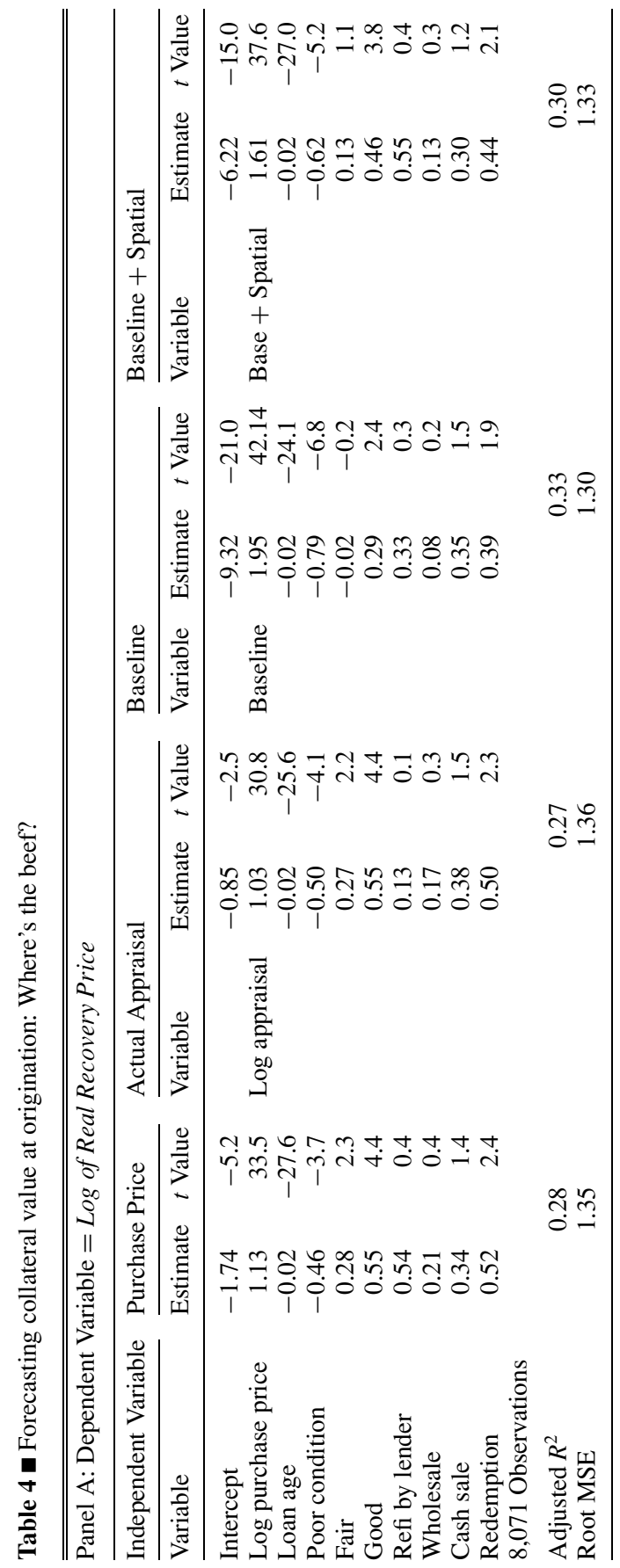




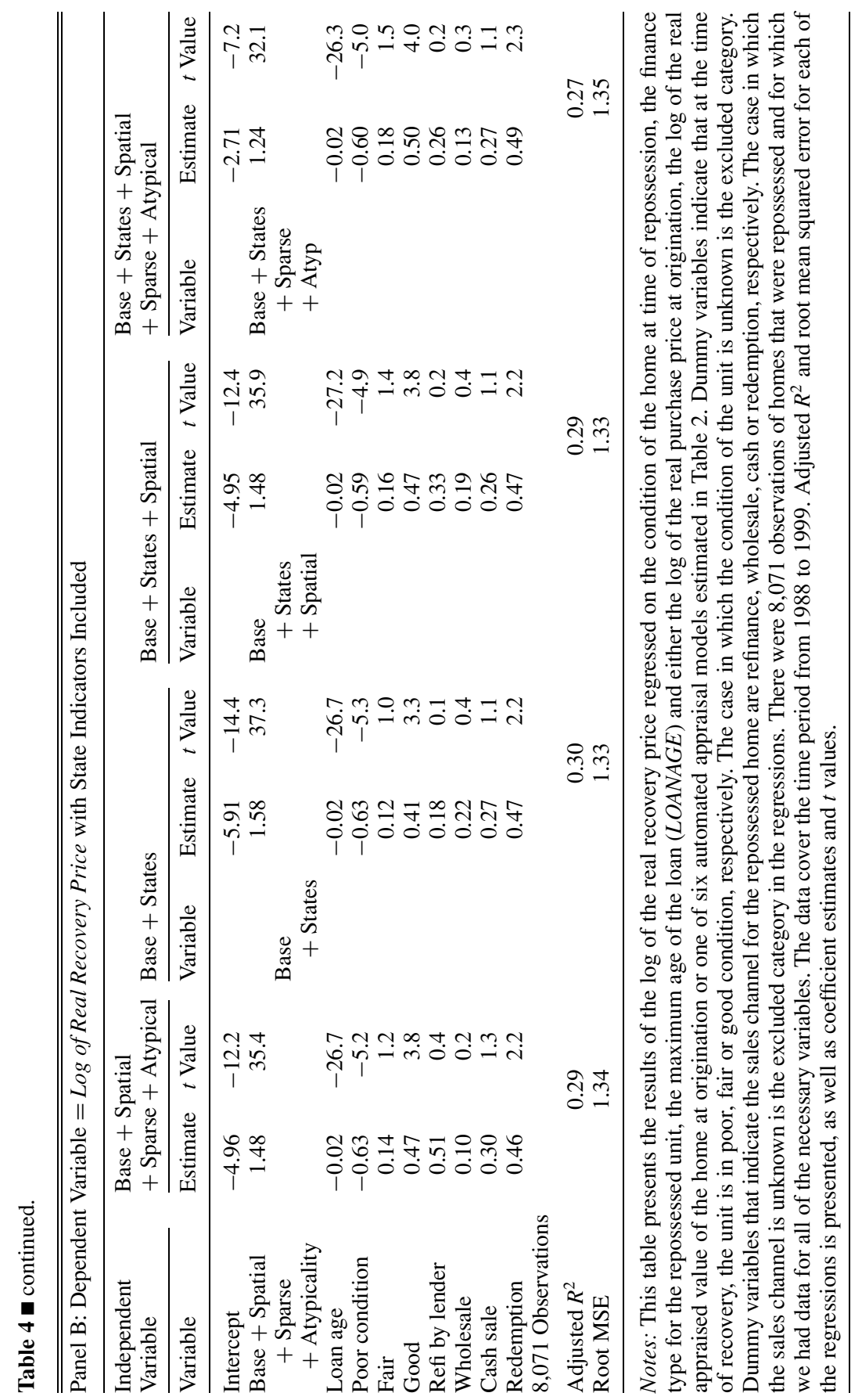


The most remarkable feature of Table 4 is that the simplest model with the worst 1-year-ahead forecasting performance in Table 3, the baseline model, is the most accurate for predicting recovery prices. This suggests that price-setting behavior in recoveries is quite different from retail pricing at origination. That is, the characteristics that the buyers of repossessions value are different from those valued by retail purchasers.

Other coefficients are similar across the equations in Table 4. Condition of the units has the expected effects, as does sales channel.

\section{Why Does Value Change in a Default?}

Table 5a probes the relationship between retail sales and recovery sales further by displaying hedonic regressions for retail prices at origination next to similar equations for recovery prices. Because the homes associated with loans that default may be different from the entire sample of homes, only the 8,071 observations for which both the origination price and the recovery price are available are included in Tables 5a-5c. Several items are noteworthy. First, age is a more important factor in a recovery sale because the implied depreciation rate is three or more times larger than the recovery sale regressions $(-0.01$ versus -0.003). Second, there are sign changes on the baths variable. Additional baths, apparently, are a liability in a recovery. This is consistent with a world where baths are in poor condition at the time of recovery or even vandalized, making rehabilitation costs higher. Third, location in a manufactured housing park is advantageous for recovered units. Units in parks may be easier to resell. Fourth, size is more important in recovery. Recovery buyers place more weight on square footage than retail buyers.

The most remarkable result, however, is the sign flip on atypicality. Unusual units trade for a premium at origination but for a very large discount in a recovery. This is very strong evidence of the effect of liquidity on the spread between origination and recovery prices. Unusual units will be more difficult to sell and on average be held longer in inventory before a sale. At the retail level, dealers will want to sell unusual units at a premium to compensate for the greater inventory expense. On the other hand, at the recovery level, dealers, expecting to have to hold unusual units for an extended period, will only purchase at a discount to compensate for the inventory costs.

\section{Cross-Equation Tests for Equality of Coefficients}

In Table 6, we test for the significance of the differences between the coefficients in the retail price (at origination) and the recovery price regressions. Only the 


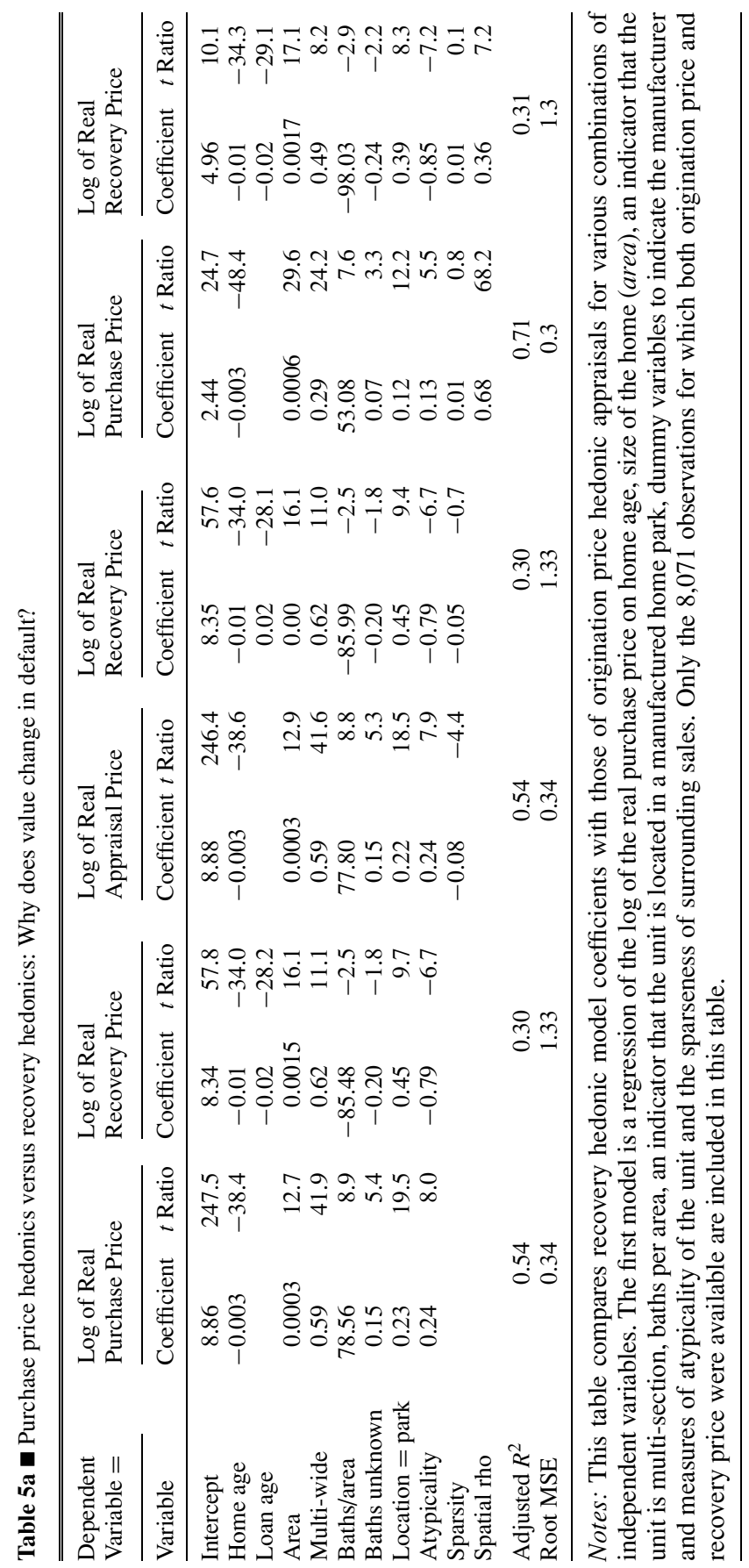


524 Capozza, Israelsen and Thomson

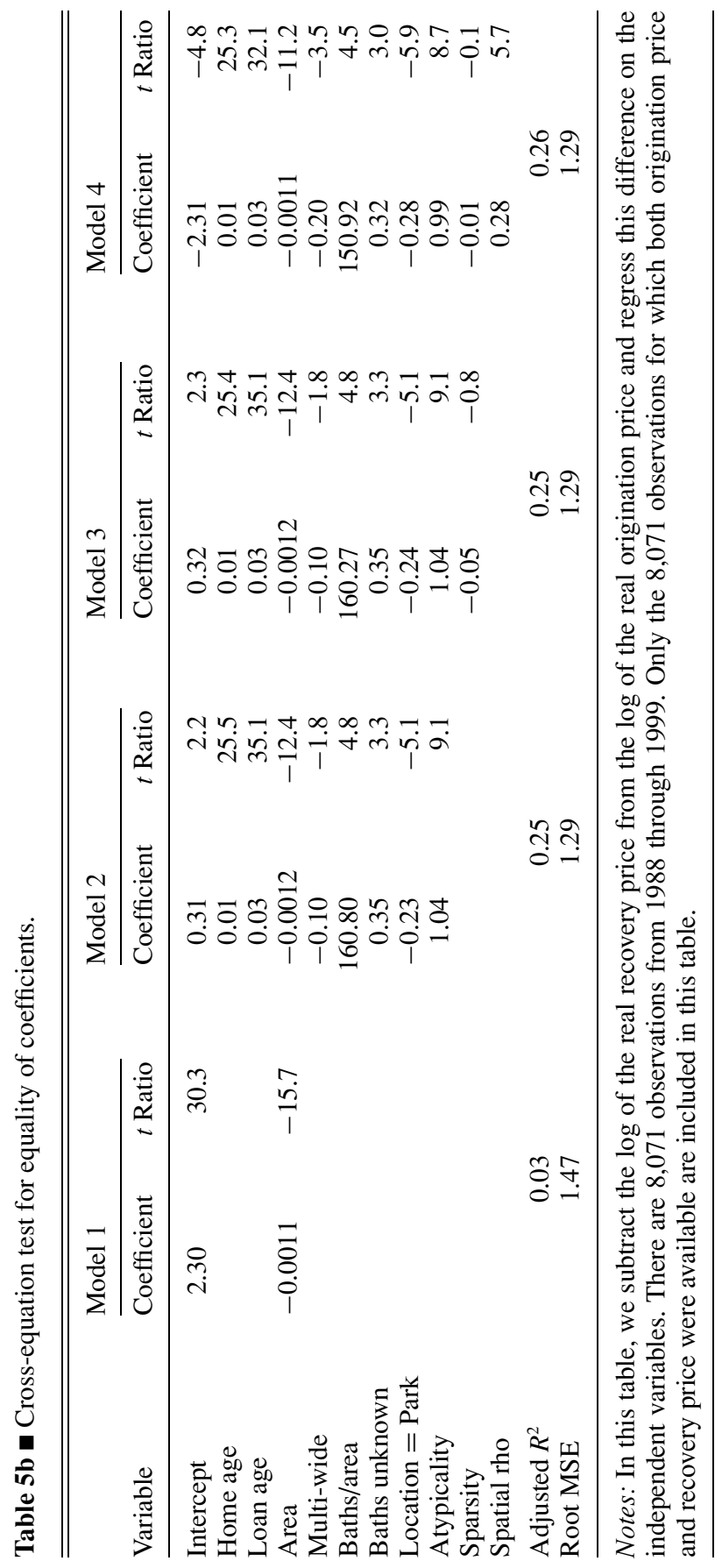




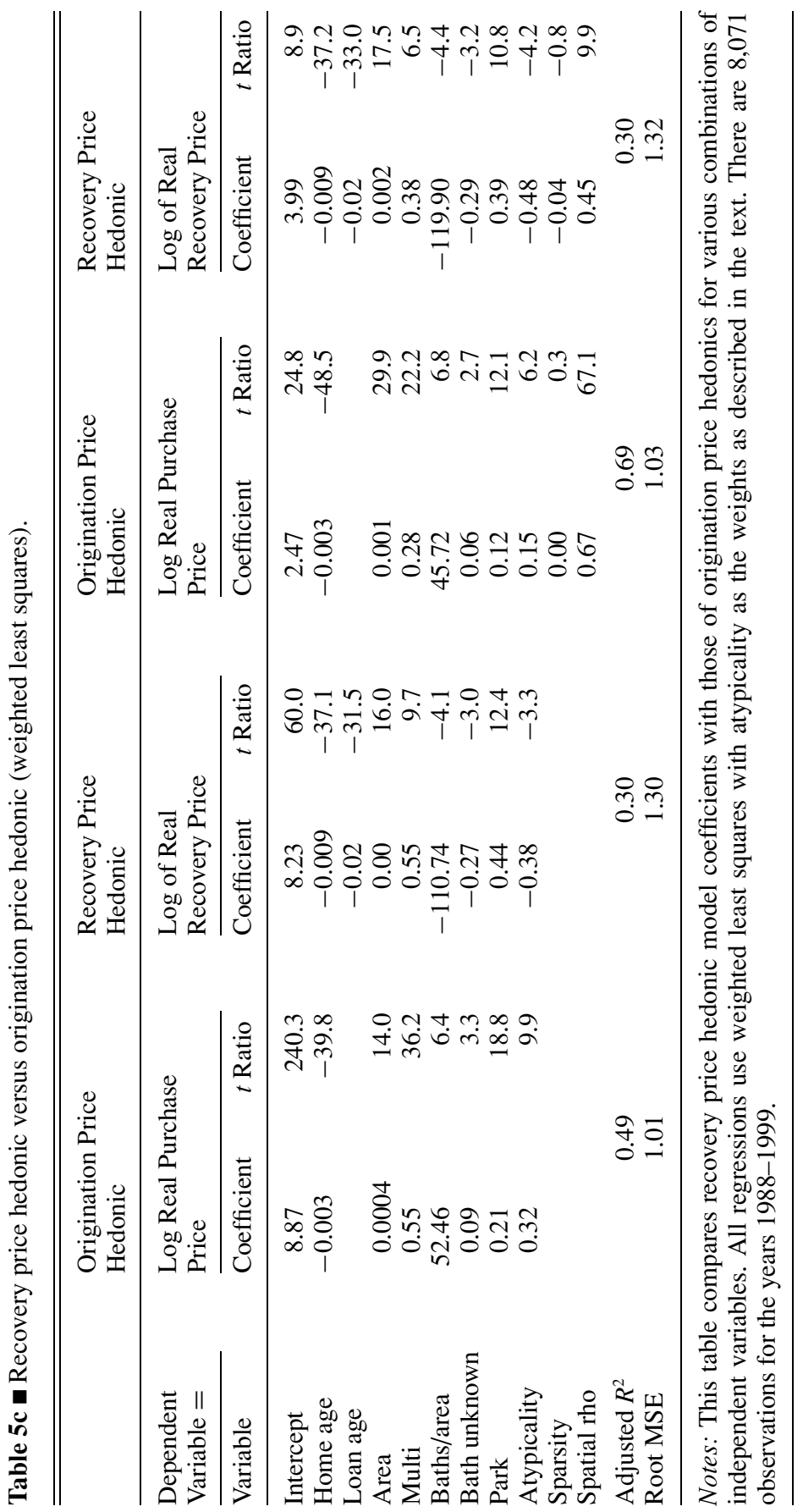


8,071 observations for which both origination price and recovery price were available are included in this table.

The most significant differences are for the depreciation rates (Home Age and Loan Age) and the unit size (Area). All the coefficient differences are significant at the usual levels except for Sparsity. These results are additional evidence that collateral values in a default are very different from values at origination. In particular, collateral values at default are not a simple additive or multiplicative transformation of values at origination. Some characteristics are more valuable, others less. In some cases, characteristics that are an asset at origination become a liability in a default.

\section{Precision Regressions: What Determines Forecast Error?}

Given the findings above that the prices (coefficients) of characteristics can vary or even change sign depending on the type of sale, we expect that the residuals from the hedonic regression might be heteroskedastic in one or more of the characteristics. Atypicality ${ }^{6}$ is a primary candidate as a possible determinant of the absolute size of residual errors.

In Table 6, we explore residual variation with Glejser regressions (see Appendix) of transformed residuals on atypicality and sparsity. In Table 6, we regress the transformed residuals from the first equation in Table 2 on measures of atypicality. Atypical (composite) is defined as:

$$
\begin{aligned}
\text { Atypical }= & \mid P_{\text {area }}(\text { Area }-\overline{\text { Area }}) \mid \\
& +\mid P_{\text {age }}(\text { Age }-\overline{\text { Age }})|+| P_{\text {width }}(\text { DMulti }-\overline{\text { Dmulti }}) \mid
\end{aligned}
$$

where $P_{i}$ are the coefficients from Model 1 in Table 2, and the bars indicate mean values. Thus, highly atypical homes are units where the weighted sums of the absolute values of these characteristics are far from their sample means. The weights are simply the implicit price weights from the Model 1 in Table 2 regression.

The results indicate that most of the explainable residual variation depends on the Atypical composite variable. Breaking this variable into its components or adding the sparsity measure does not improve the fit substantially. In the next

\footnotetext{
${ }^{6}$ Goodman and Thibodeau (1998) show that error variance tends to increase with home age and to length of time between sales, presumably because of an increased likelihood of undocumented renovations. Accordingly, we include age in our measure of atypicality.
} 


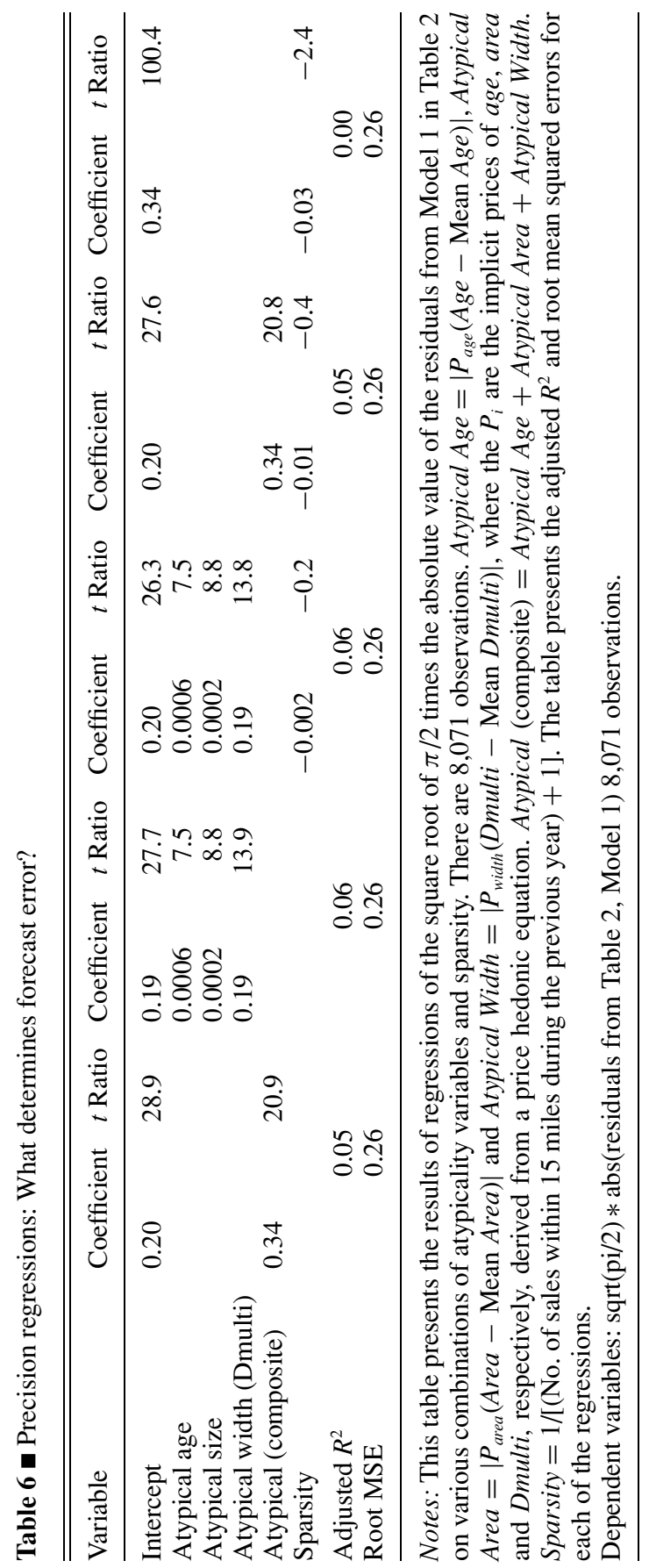


section, we use these results to re-estimate selected Table 2 and $5 \mathrm{a}-\mathrm{c}$ regressions with weighted least squares (WLS) using Atypical as the weights.

\section{Weighted Least Squares Estimates}

Table 5c presents the selected WLS regressions. Weighting the observations does affect the coefficients, presumably because the WLS estimates are more efficient. However, the qualitative results and the conclusion remain unchanged. There are still significant differences between the origination price and the recovery price coefficients.

\section{Predicting Defaults: Actual Versus Appraisal Versus Hedonic Prices}

We have now established definitively that the recovery values are different from origination values and are not a simple multiplicative transform of origination values. Lenders attempting to estimate the profitability of a loan, which depends directly on these recovery values rather than the origination values, will be best served by having estimates of recovery values independent from the appraisal at origination. In this section, we begin to analyze default probabilities using the various estimates of collateral value. In default equations, important determinants of loss rates are the initial and the subsequent LTVs (Capozza, Kazarian and Thomson 1997, 1998). The denominator of LTV is a measure of the value of the collateral and one would expect that neutral assessments of property value at origination would improve the power of LTV in a default equation. For example, we know that transaction prices in real estate are the result of bargaining between the buyer and the seller. A buyer who obtains a more favorable price may be less likely to default. Therefore, estimates of collateral value like a manual appraisal should be better for predicting defaults, because they should remove the bias from bargaining power.

On the other hand, the default decision, which is made at a later and perhaps distressed time in the life of the loan, may be driven by the liquidation values of the property. The recovery estimates should provide a better measure of recovery values.

Table 7 displays our results on the effect of the various measures of LTV. The first three columns use the actual purchase price, the manual appraisal price and the fitted origination price values, respectively, as the denominator in LTV. The analysis uses logistic regression to estimate the equations. We provide two measures of fit: pseudo-correlation, which is the correlation between the actual and the fitted values, and percent concordant that measures the ability of the models to correctly classify the observations. Both the manual or the book 


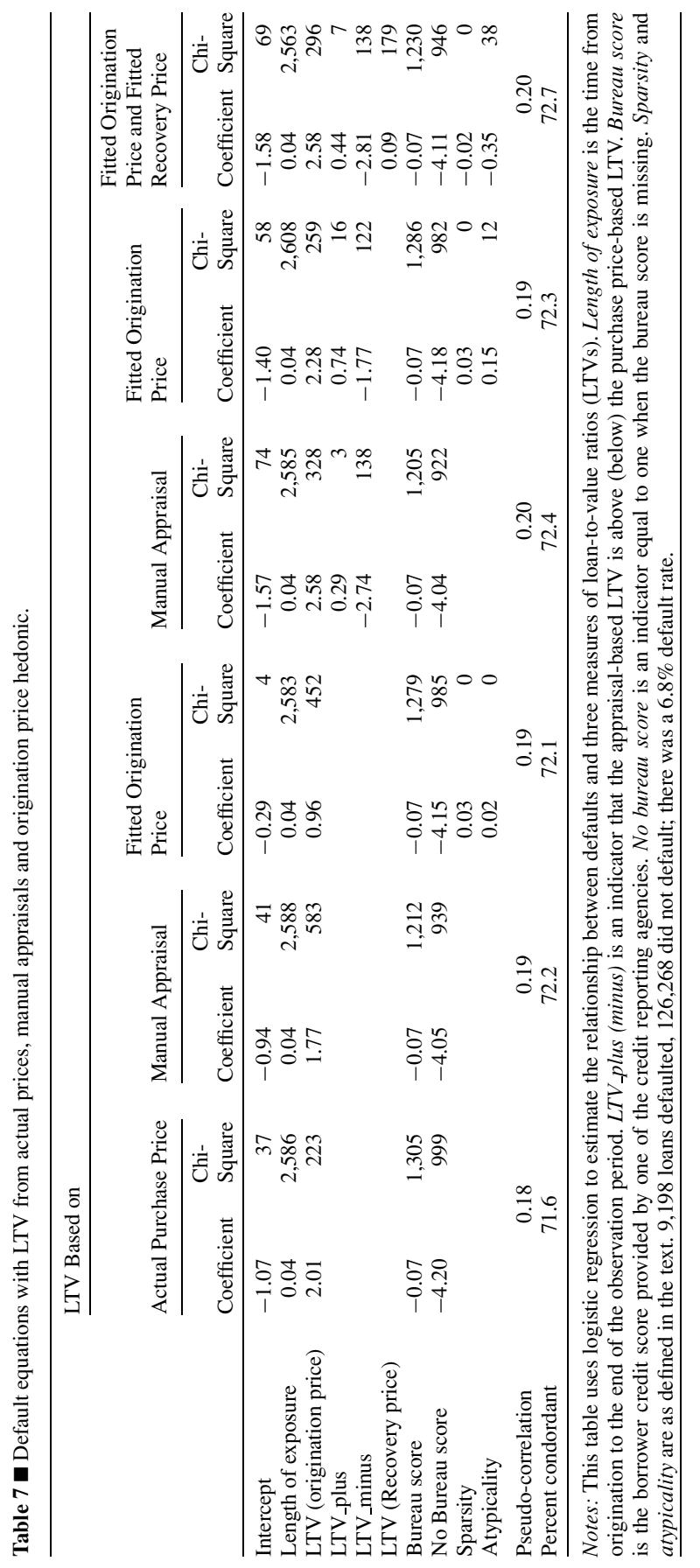


appraisal and the hedonic estimates are slightly better predictors of defaults than the actual purchase prices as expected. The manual and the hedonic appraisals are roughly comparable although the concordance is slightly $(0.1)$ higher for the manual appraisal.

In the penultimate two columns, we add variables that measure whether the appraisals are below ( $L T V_{-}$plus) or above (LTV_minus) the purchase price. In both cases, the results indicate that buyers who pay more than the neutral appraisal prices default at significantly higher rates. This implies that having a neutral assessment of the value of the property at origination, whether manual or book appraisal or statistical appraisal, is indeed beneficial for predicting defaults.

In the last two columns, we test whether the estimated recovery values affect the borrowers default decision. Earlier, we presented evidence that atypical houses sell for lower recovery values. We can also expect atypical houses to take longer to market for sale. In a default situation, there is a limited time before the borrower's equity is foreclosed. Therefore, while the recovery price is paramount in determining the losses on loans, it may also have an effect on the default probability. These last two columns are consistent with this hypothesis. Both the coefficient on the LTV from the origination price hedonic and the LTV using the recovery price hedonic are highly significant.

These results support the use of appraisals at origination. Both the manual and the statistical (automated) appraisals improve the predictive power of default equations. The last result suggests that in addition to retail value appraisals, lenders would be well served to have estimates of recovery values from a foreclosure when assessing default probabilities.

\section{Conclusions}

In this research, we have explored the relationship among purchase prices, appraised values and recovery prices for a large sample of manufactured homes in the United States. Our purpose has been to try to understand whether manual appraisals are an adequate and cost-effective adjunct to the underwriting process for mortgage lenders.

First, we show that simple hedonic models of prices at origination provide surprisingly good explanation of purchase prices, especially when spatial autocorrelation is included in the analysis. The year-ahead forecast performance of these hedonic models improves with sophistication but erodes over time. Our second set of results finds that recovery values are very different from 
origination prices. Recoveries are not a simple multiplicative transformation of origination prices. One important result is the role of atypicality, which reverses sign in the recovery price regressions. Illiquid homes sell for higher prices at origination but for large discounts in a recovery. There is also heteroskedasticity in the hedonic regressions related to the atypicality of the home. Atypical homes have a large bid-ask spread, and their prices are more difficult to explain.

Finally, we test whether defaults are best explained by purchase prices, appraised values, or recovery values. We find that indeed manual or book appraisals are a valuable adjunct to the underwriting process. There is additional information content to an appraisal for explaining defaults when the appraisal (whether manual or hedonic) price is above the purchase price, but not when below. We also find that expected recovery values have an effect on the default decision.

We thank the editor, Tom Thibodeau, the anonymous reviewers and Kelly Pace for their helpful comments and assistance.

\section{References}

Capozza, D.R., D. Kazarian and T.A. Thomson. 1997. Mortgage Default in Local Markets. Real Estate Economics 25(4): 631-655.

. 1998. The Conditional Probability of Default. Real Estate Economics 26(3): 359390.

Capozza, D.R. and T.A. Thomson. 2005. Optimal Stopping and Losses on Subprime Mortgages. Journal of Real Estate Finance and Economics 30(2): 115-131.

Chinloy, P.T., M. Cho and I.F. Megbolugbe. 1997. Appraisals, Transaction Incentives, and Smoothing. Journal of Real Estate Finance and Economics 14(1): 89-122.

Cole, R., D. Guilkey and M. Miles. 1986. Toward and Assessment of the Reliability of Commercial Appraisals. The Appraisal Journal 54(3): 422-432.

Diaz, J. III. 1997. An Investigation into the Impact of Previous Expert Value Estimates on Appraisal Judgement. Journal of Real Estate Research 13(1): 45-55.

Diaz, J. III and M.L. Wolverton. 1998. A Longitudinal Examination of the Appraisal Smoothing Hypothesis. Real Estate Economics 26(2): 349-358.

Dotzour, M.G. 1988. Quantifying Estimation Bias in Residential Appraisal. Journal of Real Estate Research 3(3): 1-12.

Glejser, H. 1969. A New Test for Heteroskedasticity. Journal of the American Statistical Association 64: 316-323.

Goodman, A.C. and T.G. Thibodeau. 1998. Dwelling Age Heteroskedasticity in Repeat Sales House Price Equations. Real Estate Economics 26(1): 151-171.

Guttentag, J.M. 1992. When Will Residential Mortgage Underwriting Come of Age? Housing-Policy-Debate 3(1): 143-156.

Hansz, J.A. and J. Diaz III. 2001. Valuation Bias in Commercial Appraisal: A Transaction Price Feedback Experiment. Real Estate Economics 29(4): 553-565. 
Haurin, D. 1988. The Duration of Marketing Time of Residential Housing. American Real Estate and Urban Economics Association Journal 16(4): 396-410.

Kinnard, W.N., M.M. Lenk and E.M. Worzala. 1997. Client Pressure in the Commercial Appraisal Industry: How Prevalent is It? Journal of Property Valuation and Investment 15(3): 233-244.

Lacour-Little, M. and S. Malpezzi. 2003. Appraisal Quality and Residential Mortgage Default: Evidence from Alaska. Journal of Real Estate Finance and Economics 27(2): 211-233.

Levy, D. and E. Schuck. 1999. The Influence of Clients on Valuations. Journal of Property Valuation and Investment 17(4): 380-400.

Noordewier, T.G., D.M. Harrison and K. Ramagopal. 2001. Semivariance of Property Value Estimates as a Determinant of Default Risk. Real Estate Economics 29(1): 127159.

Pace, R.K., R. Barry, O.W. Gilley and C.F. Sirmans. 2000. A Method for SpatialTemporal Forecasting with an Application to Real Estate Prices. International Journal of Forecasting 16: 229-246.

Quan, D.C. and J.M. Quigley. 1989. Inferring an Investment Return Series for Real Estate from Observations on Sales. American Real Estate and Urban Economics Association Journal 17(2): 218-230.

Schwert, G.W. and P.J. Seguin. 1990. Heteroskedasticity in Stock Returns. Journal of Finance 45: 1129-1155.

Wolverton, M. and P. Gallimore. 1999. Client Feedback and the Role of the Appraiser. Journal of Real Estate Research 18(3): 415-432.

\section{Appendix}

\section{Methodology}

We use the following mixed regressive spatial autoregressive model:

$$
\begin{aligned}
Y & =\rho W Y+X \beta+\varepsilon \\
\varepsilon & \sim N\left(0, \sigma^{2} I\right)
\end{aligned}
$$

where $Y$ is an $n \times 1$ vector of dependent variables, $\beta$ is a $K \times 1$ vector of parameters associated with the exogenous variables $X(n \times K$ matrix $)$, and $\rho$ is the coefficient of the spatially lagged dependent variable. The $N \times N$ matrix $W$ is a spatial weight matrix associated with a spatial autoregressive process in the dependent variable.

\section{Structure of the Spatial Weight Matrix}

To illustrate the spatial weight matrix, consider the following figure showing the spatial location of five observations. For simplicity, assume that we are only concerned about the nearest neighbor. 


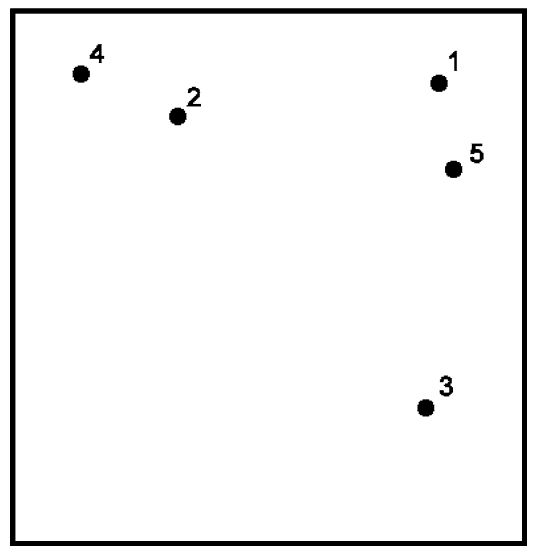

Clearly, 1 and 5 are nearest neighbors to each other as are 2 and 4.5 is the closest neighbor to 3 . In a standardized spatial weight matrix, each row must sum to 1 . The $i j$ th matrix entry will be a 1 if the nearest neighbor to the $i$ th observation is the $j$ th observation. Otherwise, it will be a 0 . In our example,

$W=\left[\begin{array}{lllll}0 & 0 & 0 & 0 & 1 \\ 0 & 0 & 0 & 1 & 0 \\ 0 & 0 & 0 & 0 & 1 \\ 0 & 1 & 0 & 0 & 0 \\ 1 & 0 & 0 & 0 & 0\end{array}\right]$

Note that $W$ might not be symmetric. In this case, 5 is the closest neighbor to 3, but the reciprocal is not true. Note also that the diagonal is zero. This is because an observation cannot be its own nearest neighbor. Using this $W$, we get:

$W Y=\left[\begin{array}{lllll}0 & 0 & 0 & 0 & 1 \\ 0 & 0 & 0 & 1 & 0 \\ 0 & 0 & 0 & 0 & 1 \\ 0 & 1 & 0 & 0 & 0 \\ 1 & 0 & 0 & 0 & 0\end{array}\right] \cdot\left[\begin{array}{l}y_{1} \\ y_{2} \\ y_{3} \\ y_{4} \\ y_{5}\end{array}\right]=\left[\begin{array}{l}y_{5} \\ y_{4} \\ y_{5} \\ y_{2} \\ y_{1}\end{array}\right]$

Now let us see what happens when we consider the two nearest neighbors and weight them equally. The second nearest neighbor to 1 is 2 and vice versa. The second nearest neighbor to 3 and 4 is 1 , and the second nearest neighbor to 5 is 3. Now, $W$ looks like: 


$$
W=\left[\begin{array}{lcccc}
0 & 1 / 2 & 0 & 0 & 1 / 2 \\
1 / 2 & 0 & 0 & 1 / 2 & 0 \\
1 / 2 & 0 & 0 & 0 & 1 / 2 \\
1 / 2 & 1 / 2 & 0 & 0 & 0 \\
1 / 2 & 0 & 1 / 2 & 0 & 0
\end{array}\right]
$$

Note that the rows still sum to 1 . Multiplying this matrix by $Y$, we get:

$$
W Y=\left[\begin{array}{ccccc}
0 & 1 / 2 & 0 & 0 & 1 / 2 \\
1 / 2 & 0 & 0 & 1 / 2 & 0 \\
1 / 2 & 0 & 0 & 0 & 1 / 2 \\
1 / 2 & 1 / 2 & 0 & 0 & 0 \\
1 / 2 & 0 & 1 / 2 & 0 & 0
\end{array}\right] \cdot\left[\begin{array}{l}
y_{1} \\
y_{2} \\
y_{3} \\
y_{4} \\
y_{5}
\end{array}\right]=\left[\begin{array}{c}
(1 / 2)\left(y_{2}+y_{5}\right) \\
(1 / 2)\left(y_{1}+y_{4}\right) \\
(1 / 2)\left(y_{1}+y_{5}\right) \\
(1 / 2)\left(y_{1}+y_{2}\right) \\
(1 / 2)\left(y_{1}+y_{3}\right)
\end{array}\right]
$$

So, $W Y$ is just an average of the dependent variable of the two nearest neighbors. If we give the nearest neighbor a weight of $2 / 3$, and the second nearest neighbor a weight of $1 / 3$, we get:

$$
W Y=\left[\begin{array}{ccccc}
0 & 1 / 3 & 0 & 0 & 2 / 3 \\
1 / 3 & 0 & 0 & 2 / 3 & 0 \\
1 / 3 & 0 & 0 & 0 & 2 / 3 \\
1 / 3 & 2 / 3 & 0 & 0 & 0 \\
2 / 3 & 0 & 1 / 3 & 0 & 0
\end{array}\right] \cdot\left[\begin{array}{l}
y_{1} \\
y_{2} \\
y_{3} \\
y_{4} \\
y_{5}
\end{array}\right]=\left[\begin{array}{c}
(1 / 3)\left(y_{2}+2 y_{5}\right) \\
(1 / 3)\left(y_{1}+2 y_{4}\right) \\
(1 / 3)\left(y_{1}+2 y_{5}\right) \\
(1 / 3)\left(y_{1}+2 y_{2}\right) \\
(1 / 3)\left(2 y_{1}+y_{3}\right)
\end{array}\right]
$$

which is a weighted average of the dependent variable of the two nearest neighbors.

In the current study, we restricted the rows of the spatial weight matrix, $W$, to sum to 1 . Because we only wanted to model the influence of previously sold neighboring homes, we chose the 15 nearest observations occurring within the previous year and weighted them (as in Pace, Barry, Gilley and Sirmans 2000) via:

$$
W_{i j}=\left(\begin{array}{ll}
\frac{0.75^{l}}{\sum_{l=1}^{15} 0.75^{l}} & \text { if } j \text { is the } l \text { th nearest observation to } i, \text { and } l \leq 15 \\
0 & \text { otherwise }
\end{array}\right.
$$

Because most of the entries of $W$ are zero, we were able to use sparse matrix routines, which saved a considerable amount of computational space. We dropped 
the first year of observations after creating the spatial weight matrix. We did this because the estimator could perform poorly initially, as it would have a very small selection of previously sold neighbors to use in the first predictions.

\section{Maximum Likelihood Estimation:}

Equation (A.1) can be represented as:

$A y=X \beta+\varepsilon$

where $A=I-\rho W$.

Solving for $\varepsilon$, we get:

$A y-X \beta=\varepsilon$.

This is a nonlinear expression where $\varepsilon$ is a vector of independent normal error terms. Although the error term has a well-behaved joint distribution, it cannot be observed, and the likelihood function has to be based on $y$. Therefore, it is necessary to introduce the concept of a Jacobian, which allows us to derive the joint distribution for the $y$ from that for the $\varepsilon$. The Jacobian for the transformation of the vector of random variables $\varepsilon$ into the vector of random variables $y$ is:

$J=\operatorname{det}(\partial \varepsilon / \partial y)=|A|=|I-\rho W|$.

The density function of a joint normal distribution with mean zero and variance $\sigma^{2} I$ is:

$f(\varepsilon)=\frac{1}{(2 \pi)^{N / 2}\left|\sigma^{2} I\right|^{1 / 2}} \exp \left\{-\frac{\varepsilon^{\prime} \varepsilon}{2 \sigma^{2}}\right\}$.

Using the change of variable technique with Equations (A.3), (A.4) and (A.5), we can find the density function for $y$ :

$$
\begin{aligned}
f(y)= & \frac{1}{(2 \pi)^{N / 2}\left|\sigma^{2} I\right|^{1 / 2}} \\
& \times \exp \left\{-\frac{1}{2 \sigma^{2}}(A y-X \beta)^{\prime}(A y-X \beta)\right\} \cdot|I-\rho W| .
\end{aligned}
$$

Taking natural logarithms of both sides, we get the following log-likelihood function: 


$$
\begin{aligned}
L= & -\left(\frac{N}{2}\right) \ln (2 \pi)-\left(\frac{N}{2}\right) \ln \left(\sigma^{2}\right) \\
& -\frac{1}{2 \sigma^{2}}(A y-X \beta)^{\prime}(A y-X \beta)+\ln |I-\rho W| .
\end{aligned}
$$

In general, maximizing the log-likelihood of $y$ would amount to minimizing the sum of squared errors, $(A y-X \beta)^{\prime} /(A y-X \beta)$, were it not for the term involving the determinant of the Jacobian. However, in our case $W$ is lower triangular with zeros on the diagonal, so $A=I-\rho W$ is lower triangular with ones on the diagonal. The determinant of a lower triangular matrix is simply the product of the elements of its diagonal. Therefore, the log-determinant of $A$ is 0 . So, due to the structure of the spatial weight matrix, ordinary least squares is the maximum likelihood estimate.

\section{Atypicality}

Following Haurin (1988), we created a variable to account for the difficulty that arises in valuing homes with unusual features. We use implicit marginal prices from a price hedonic regression of home sales prices on various characteristics to penalize absolute deviations from the average. We then aggregate these values. Our measure of atypicality for the $i$ th home is as follows:

$$
\begin{aligned}
A T Y P_{i}= & \left|P_{A R E A}\left(A R E A_{i}-\overline{A R E A}\right)\right|+\left|P_{A G E}\left(A G E_{i}-\overline{A G E}\right)\right| \\
& +\left|P_{\text {DMULTI }}(D M U L T I-\overline{D M U L T I})\right|
\end{aligned}
$$

where $P_{A R E A}=0.00063446, P_{A G E}=-0.00257$ and $P_{D M U L T I}=0.34933$ are implicit marginal prices obtained from a regression of log of real purchase price on AREA, AGE and DMULTI, and where $\overline{A R E A}, \overline{A G E}$ and $\overline{D M U L T I}$ are the sample means for area, home age and for the multi-wide dummy variable, respectively.

\section{Glejser Test}

We use the Glejser test (Glejser 1969, Schwert and Seguin 1990) to detect heteroskedasticity in our model. In the first stage, we estimate the model:

$$
\begin{aligned}
y_{i} & =\rho w_{i} Y+x_{i} \beta+\varepsilon_{i} \\
\varepsilon_{i} & \sim N\left(0, \sigma_{i}^{2}\right)
\end{aligned} \quad i=1,2, \ldots, n
$$


We then use the residuals from this regression, $e=Y-\hat{Y}$, in a Glejser regression:

$(\pi / 2)^{1 / 2}|e|=X \beta+v$.

We use $(\pi / 2)^{1 / 2}|e|$ as an estimate of the standard deviation of $e$. If $e_{i} \sim$ $N\left(0, \sigma_{i}^{2}\right)$, then $E\left[(\pi / 2)^{1 / 2}\left|e_{i}\right|\right]=\sigma_{i}$. So, we are regressing the estimated variance on our independent variables. We find that the variable atypicality is the source of the heteroskedasticity, and we run a weighted least squares regression (WLS) of the model in Equation (A.9) using atypicality as the weight. 